\title{
Valuing the Impacts of Landslides: A Choice Experiment Approach
}

\author{
Elin Spegel ${ }^{1} \cdot$ Kristina $\mathbf{k}^{1}$
}

Received: 13 March 2021 / Accepted: 15 October 2021 / Published online: 17 November 2021

(c) The Author(s) 2021

\begin{abstract}
This paper analyzes the preferences for reducing the negative impacts of landslides. Negative consequences of landslides include impacts on transport infrastructure, humans, the environment and important societal services. We apply a choice experiment. The analysis is based on 6048 observations from 504 participants in a web panel. The overall finding is that reducing the risk of landslides would have a positive impact on individuals' utility, and that individuals prioritize preventing negative consequences on human health and safety over maintaining societal services, environmental status, and preventing damages to transport infrastructure, which seems to be least pressing. Results indicate that prioritizations of citizens differ from the prioritizations of public authorities, whose risk assessment model for evaluating the consequences of landslides gives equal weight to the different impacts.
\end{abstract}

Keywords Impacts of natural hazards $\cdot$ Choice experiment $\cdot$ Landslide risks $\cdot$ Risk preferences

\section{Background}

Extreme weathers and impacts caused by landslides and floods are likely to become more frequent and severe in the future as a result of climate change (IPCC 2014). Natural disasters generate significant costs in the form of damaged property and infrastructure but may also have negative impacts on humans and the environment. This paper focuses on how different impacts of landslides are valued. The purpose is to elicit the preferences and willingness to pay for reductions in some of the consequences of landslides. Methodologically we apply a choice experiment approach.

Although the literature on the social costs of climate change is substantial, studies on the valuation of impacts caused by extreme weather, and in particular landslides, are scarcer. There are studies focusing on landslide effects and the willingness to re-settle from landslide prone areas in developing countries (Charoenphong 1991; Mertens et al. 2018; Vlaeminck et al. 2016). When Vlaeminck study the willingness to re-settle from landslide prone areas in Uganda, they find that people living in high risk areas (on steep slopes or

Kristina Ek

kristina.ek@1tu.se

1 Luleå University of Technology, Luleå, Sweden 
in villages that have already been affected by landslides) are more willing to re-settle than people living in low-risk areas (Vlaeminck et al., 2016). It has also been found that wealthier households are more willing to re-settle than poorer households and that institutional factors such as trust in institutions are important for the willingness to re-settle in Cameroon (Baert et al. 2020).

In a European context, there are studies on the societal impacts of landslides focusing on e.g. Italy, Norway, Switzerland and the UK. To the best of our knowledge there is no previous study on the preferences for reducing landslide risk in Sweden. Flügel et al. (2015) apply a choice experiment to examine how car drivers in Norway value landslide risks compared to road accident risks. Vranken et al. (2013) use a restoration method approach to estimate (a lower bound for) landslide costs in Belgium. They find that reconstruction of roads and railroads damaged after landslides constitute an important part of these costs. Mattea et al. (2016) use a choice experiment to examine whether visual information affects preferences for different devices that can be used to reduce landslide risk in the Italian Alps. Their results show that visual information contribute to higher willingness-to-pay for the measure for which information was provided and they thus conclude that education may increase peoples' willingness to pay for measures to reduce landslide risk (Mattea et al. 2016). Franceschinis et al. (2020) use the same data as Mattea et al. (2016) but apply a Latent Class model to analyze preference heterogeneity across groups. They find women with higher education and income more likely to belong to the class with a higher willingness to pay for all devices. When Thiene et al. (2017) analyze how subjective perceptions about the probabilities (for instance that a landslide will occur, and that people will die as a result) differ from science-based probabilities, they find that respondents overestimate these probabilities also after receiving information about the science-based estimates (in particular their own chance of dying were hugely overestimated). In a second step, Thiene et al. (2017) use the subjective risk perceptions in a choice experiment in which participants could choose between different types and levels of risk reductions, results reveal that that larger risk reductions, compared to baseline, were significant in explaining choices.

Based on a review on the socio-economic consequences of natural disasters, Allaire (2018) argue that the evaluation of impacts is mainly focused to damages on infrastructure and property, while non-tangible impacts on health and public services are largely omitted. The aim of this study is to contribute with such knowledge in a Swedish context. Sweden has many relatively small municipalities (in number of citizens) and local decision structures; local authorities and decision makers often work simultaneously with different issues related to land and water use - sometimes with conflicting policy goals. Thus, the environmental values held by the citizens constitute important input for decision makers and public officials involved in climate change adaptation, such as undertaking measures aimed to reduce future landslide risk. This is where the present study contributes, by focusing on preferences closely linked to the same criteria used by the public authorities. These criteria - which are used as attributes in the choice experiment-include impacts on: human life, the environment, infrastructure, and on important societal services. Due to geological and hydrological characteristics, the Gothenburg region in the south-western part of the country is the most vulnerable to landslides and flooding. Most of previous landslides in the country have occurred in proximity to the Göta River and as a result of expected changes in precipitation in combination with continued urbanization this region is expected to be even more severely affected by landslides and flooding in the future (e.g. Kiilsgaard et al. 2015; Swedish Geotechnical Institute 2016; SOU, 2007:60). We use the Göta River area as our case study but will evaluate how different impacts are valued in a somewhat generic context, i.e. participants are asked to choose between alternatives describing different impacts 
of landslides in their municipality without specifying the context in detail for each municipality, instead the attributes and levels are selected to be considered reasonably realistic in each municipality in the region. This helps us to empirically challenge whether the different impacts are equally weighed as (implicitly) assumed in the assessments of the public authorities. Since policy makers and officials involved in mitigating or adapting society to the consequences of climate change often need to prioritize between different policies and measures, knowledge about how different types of impacts are valued in relative terms is highly relevant for the implementation of resource efficient risk reducing policies. If citizens do not consider different types of consequences equally important, decisions based on such (implicit) assumptions will lead to inefficient use of societal resources.

\section{The Survey}

\section{The Göta River Area}

The casualties after heavy rains, floods and earthquakes, are often a result of the landslides caused by these events. With regard to loss of lives, developing countries in Asia are most severely affected by landslides, while material damage generally dominates in industrialized countries (e.g. Kirschbaum et al 2010). The choice experiment in this study is implemented in five municipalities (Ale, Gothenburg, Kungälv, Lilla Edet, Vänersborg and Trollhättan) located close to the Göta River in the southwestern part of Sweden. In Sweden, landslides covering more than one hectare occur on average every two to three years (Swedish Civil Contingencies Agency, 2021) and this area, in the southwest of the country, is the region most vulnerable to landslides and flooding in Sweden. The most severe landslide in the country occurred here in 1977, when 9 persons were killed, 62 more were injured and 62 houses were destroyed (Swedish Civil Contingencies Agency 2017). Due to climate change and continued urbanization, the Gothenburg region is expected to be increasingly affected by landslides and flooding in the future. Mitigation measures and adapting policies are therefore high on the political agenda (e.g. Kiilsgaard et al. 2015; Swedish Geotechnical Institute, 2012; Swedish Geotechnical Institute 2016; SOU, 2007:60).

\section{Survey development}

The survey consisted of three parts. The first part included questions about previous experience, knowledge and concern regarding landslides, together with questions about attitudes towards different societal and environmental hazards. The second part included the choice experiment. The choice tasks were preceded with information about possible impacts on society from landslides. The last part of the questionnaire collected socio-demographic information. Experts from the Swedish Geotechnical Institute, which is the national authority responsible for preventing landslide risk in Sweden, supported the development of the survey. The survey development was also supported by a number of smaller pre-tests; 6 local residents living close to the Göta River participated in individual pre-tests, and one pilot was conducted with a group of eight Ph.D. students. The number of levels of the attributes was reduced after the pre-tests, and some minor clarifications and changes in formulations were also made after these pre-tests. The main lesson from the pre-tests was 
however that after the number of levels had been reduced the choice task seemed to be understandable and manageable for participants.

\section{The choice experiment}

Defining the attributes to be included in the choice experiment and their corresponding levels is clearly important; selected attributes must be relevant from a policy perspective and understandable from the individual participant's perspective. In this study the attributes are based on the same criteria as used by the Swedish Geotechnical Institute (SGI) in their assessment of landslide risks (see e.g., Kiilsgaard et al. 2015). The criteria are landslide impacts on: human life (number of people affected), the environment (e.g. water pollution), transport infrastructure (e.g., type of road/railway affected), and on important societal services (e.g. hospitals, drinking water production). Each criterion in the risk assessment made by the Swedish Geotechnical Institute ranges from 1 to 5, where 1 corresponds to no or very small consequences, 2 to large consequences, 3 to very large consequences, 4 to extremely large consequences, and 5 corresponds to what is called catastrophic consequences. Table 1 shows the definitions of the levels of damage used by the SGI (Kiilsgaard et al., 2015, our translation).

The definitions as presented in Table 1 were not considered specific enough to be used as they are as levels in a choice experiment. In order to make the choice task comprehensive and feasible for participants, the description of the attributes and their corresponding levels were modified and somewhat simplified compared to the criteria used by public officials. The impact "number of people injured or killed" was called "impacts on human life" in the choice experiment. There are however not large railway stations or schools in all municipalities and no large sports arena in any of the municipalities, and it would thus not be meaningful to include the extremely large or catastrophic outcomes. Levels four and five were therefore omitted and the number of levels was reduced from five to three, in order for participants to consider the outcome as understandable and reasonable. The remaining levels, one, two and three, were presented similarly as in the risk assessment made by the public authority, yet with specific numbers of people injured or killed $(0,10,50)$.

In the pre-tests, participants found it difficult to comprehend the differences in the levels of the attributes "impacts on the environment" and "impacts on societal services". After some iterations, these attribute were given two levels instead of five. Respondents were informed that a landslide could - but must not - have a negative impact on the environment (due to e.g. hazardous substances contaminating water and soil) and on societal services (participants were told that societal services were either affected for about a month or unaffected). Finally, the attribute "impact on transport infrastructure" had three levels since also in this case, some of the initial levels as defined in the risk assessment were fairly similar and hard to distinguish from each other.

Each choice set comprised three alternatives (A, B and C). Alternative $\mathrm{C}$ was the business as usual alternative (BAU), with no measures implemented to reduce landslide risk (see Table 2). Alternative $\mathrm{C}$ did not imply any cost. It should be noted that the nonmonetary attribute levels in alternative $\mathrm{C}$ are also hypothetical as they correspond to the more severe consequences, scoring relatively high in the risk assessments made by the SGI. The outcome in alternative $\mathrm{C}$ is however considered realistic in the future by the authorities, due to climate change (e.g. Kiilsgaard et al. 2015; Swedish Geotechnical Institute 2016). 


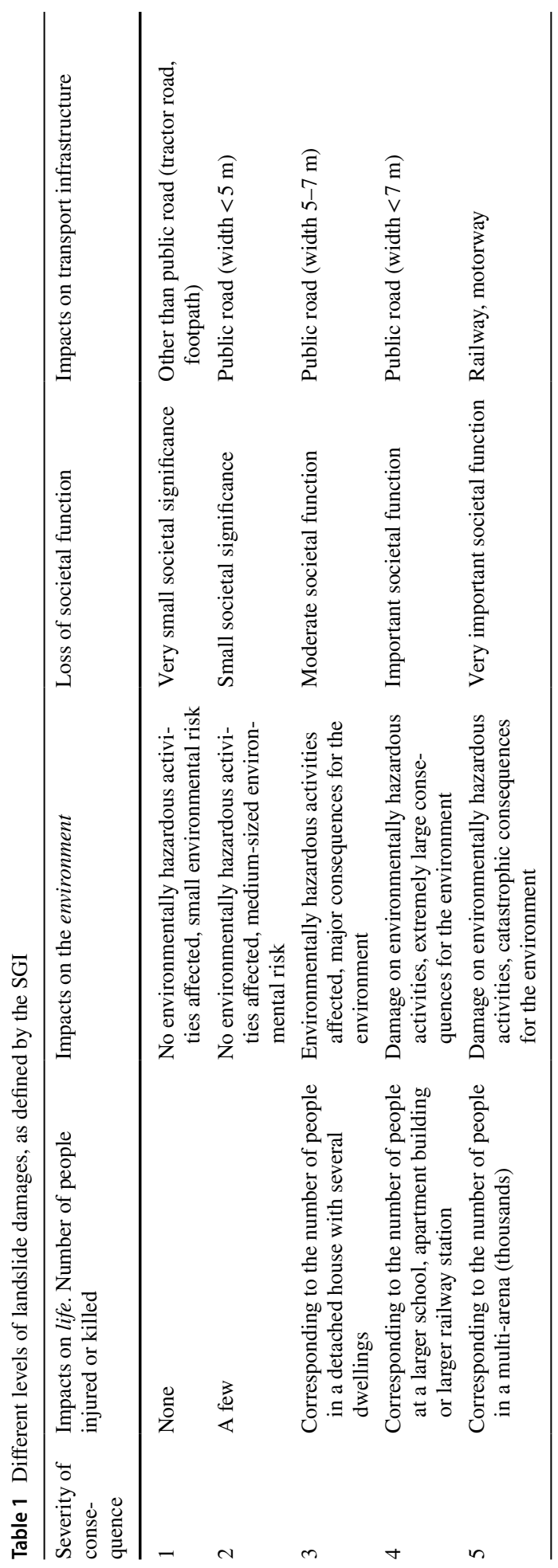




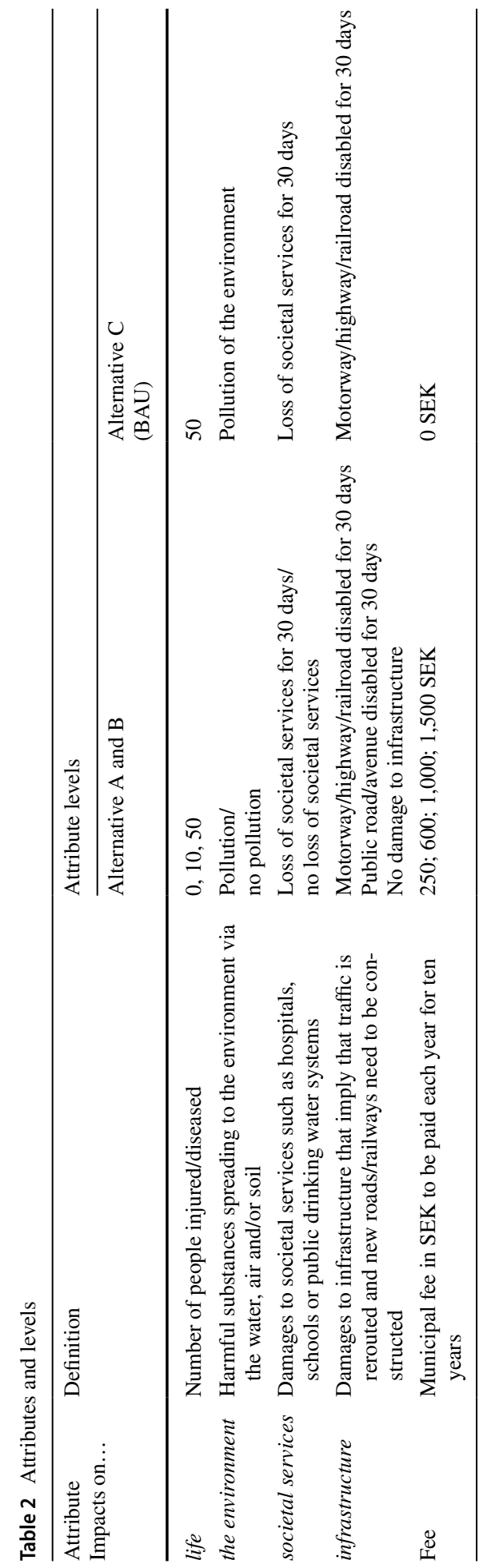


Alternatives A and B correspond to scenarios where measures towards reducing the risk of landslides have been undertaken. Respondents were told that these alternatives could be financed through an annual fee that, if implemented, would be paid by all households in their municipality for the coming ten years. It would take considerable time and financial resources (about 5-6 billion SEK) to implement measures aimed at reducing the risk of landslides in the Göta River valley as it stretches alongside $186 \mathrm{~km}$ of riversides (Swedish Geotechnical Institute 2012). A timeframe of ten years was therefore considered long enough to be perceived as reasonable realistic.

Results from previous research about the impact of uncertainty and risk on environmental preferences are somewhat ambiguous; Veronesi et al. (2014) did not find preferences to be sensitive to the level of probability of occurrence, but there are other studies, such as Drake et al. (2013), Bartczak and Meyerhoff (2013) and Rolfe and Windle (2015) reporting that preferences over changes in environmental quality are sensitive to probabilities. We analyze the impact of changes in probabilities on preferences by varying the probabilities in the choice experiment scenarios. In the first choice set, the respondent was asked to make a choice between the three alternatives $\mathrm{A}, \mathrm{B}$ or $\mathrm{C}$ given that the probability that a landslide would occur during the coming period of ten years was 10 percent. After choosing the preferred alternative in the initial choice set the respondent faced a follow-up question, in which she/he was asked whether she/he would change the choice in the previous question if the probability of a landslide would either increase to 50 percent or decrease to 1 percent. Communicating probabilities in a way that is comprehensive for citizens in general is not trivial, it can be done by using probabilities or by using verbal expressions, and these can be combined as well (both the IPCC and the Swedish authorities use mainly verbal expressions such as unlikely, likely, very likely etc.). Verbal risk communication can however also be problematic (Harris and Corner 2011). Probabilities were used in the choice experiment and the follow-up question, as they were considered to be more distinct. In the follow-up questions, the changes in probabilities were quite large, and although the results of the pre-tests did not indicate that they were considered unrealistic, these pre-tests were quite limited in size and it is possible that this was the case, not least for the increase from 10 to 50 percent.

The respondent could answer yes, and change to another alternative (the alternatives then appeared again), no, or I don't know. ${ }^{1}$ The motive for varying the level of risk in the scenarios rather than including risk as one of the attributes, like in Veronesi et al. (2014), Drake et al. (2013), and Cadavid and Ando (2013), was to facilitate the choice tasks. Choosing between alternatives that includes probabilities can be mentally cumbersome for respondents (Logar and Brouwer 2016; Corso et al. 2001). By altering the probability of an event between the choice sets, rather than between the alternatives within a choice set, the participant is given time to reflect on the differences of the impacts of a landslide and the probability of an event separately.

The final design of the choice experiment was constructed using Ngene software. We apply an efficient design. By using prior information achieved from the two pilot tests, the efficient design avoids dominant alternatives and minimizes the correlation between attributes levels. By doing so, the efficient design can generate model estimates with small standard errors (Ferrini and Scarpa 2007; Rose and Bliemer 2013; Sándor and Wedel

\footnotetext{
1 The second choice task introduced two possible choices to the respondents; i.e. to reflect over whether they would like to change their choice when the level of risk changed and, if so, to evaluate the attributes and levels once again. As probabilities may be considered an abstract concept, we introduced the "I don't know" alternative in the follow-up question to allow uncertain respondents to "opt out" from the choice whether to change their preferred alternative or not.
} 
2001; Scarpa and Rose 2008). Because information (priors) is available with some degree of uncertainty, a Bayesian D-error approach, assuming normally distributed priors, was used. The final experimental design consisted of 12 choice sets, divided in two blocks. Each individual answered 12 choice sets, 6 "initial" choice sets (with a 10 percent probability of a landslide) and 6 "follow-up" choice sets (with either a 1 percent or a 50 percent probability of a landslide). Hence, only the probability of a landslide changed between the initial choice questions and the follow-ups, while all attributes and levels were equal. The increase/decrease of probabilities in the follow up questions was randomly assigned; there were two versions of each block, where the first version of each block contained the randomized assignment of probabilities to the follow-up questions, and in the second version the assignment of probabilities was inverted. Table 3 gives an example of a choice set and follow-up question, in this example the respondent chose alternative $\mathrm{A}$ in question 1 , and alternative $\mathrm{B}$ in the follow-up question. With regard to Alternative $\mathrm{C}$, is should be noted that the BAU is somewhat different from a traditional status-quo alternative in most choice experiments. If no measures to prevent the impacts of landslides are undertaken, the expected consequences are increasing, due to climate change. Therefore, Alternative $\mathrm{C}$ represents a hypothetical, yet likely, outcome during the coming 10 years if no measures are undertaken.

\section{Results}

\section{Data Collection and Descriptive Statistics}

Data was collected in June 2017, via a web panel, administered by the company Norstat. The panel contains approximately 90,000 members, who are randomly recruited by telephone. There are possible issues stemming from any differences in characteristics of those who choose to be a part of the panel and the rest of the population (Bethlehem 2009). Such potential problems include professional survey-takers, self-selection bias and under-coverage of individuals without Internet access. The latter may however be a limited problem in Sweden as most individuals have since long had access to Internet and use the Internet frequently. The sample consists of panel members residing in the municipalities around the Göta River (namely Ale, Gothenburg, Kungälv, Lilla Edet, Trollhättan and Vänersborg). In total 1894 panel members were invited to answer the survey, out of which 504 responded (126 respondents per block), corresponding to a response rate of 27 percent, which is comparable with other surveys using web panels (Elgan and Leifman 2013; Svensson 2013).

The socio-demographic characteristics of the sample presented in Table 4 show that the gender and age distributions in the sample are similar to the corresponding regional averages (Statistics Sweden 2016). The respondents are however, on average, more educated then the regional population in general. Although the statistics for income levels are not entirely comparable (as the sample household incomes are given as ranges rather than as specific numbers), the households in the sample seem to have somewhat higher incomes than the regional averages. The regional population average lies however within one standard deviation of the mean for the respondent sample.

The survey also included questions about previous experiences of and knowledge about landslides. 18 percent of the respondents report that they, or someone they know, have been affected by landslides. When asked whether they had received any information about the risk of landslides by the municipality, six percent had received such information. The 


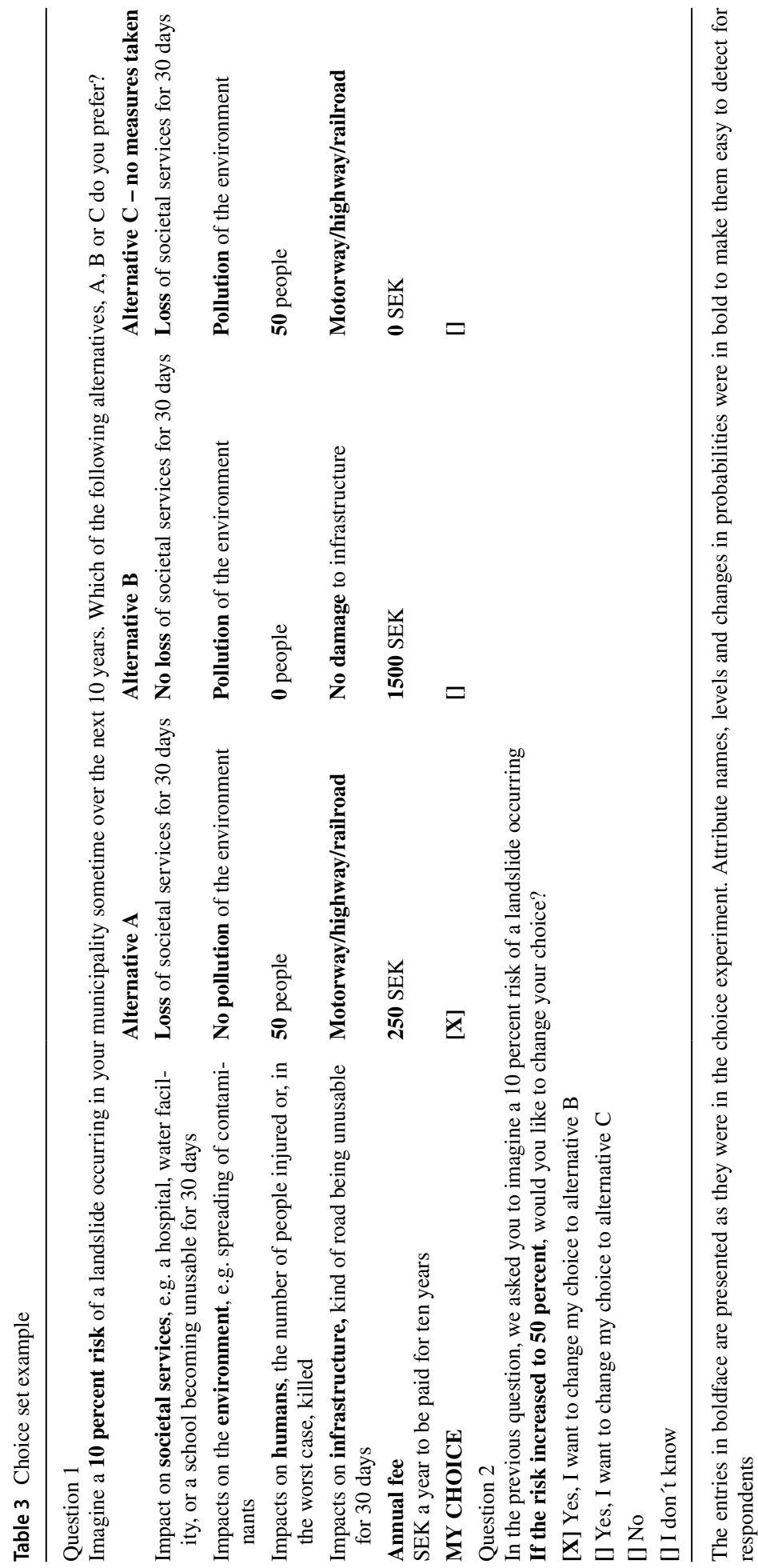


Table 4 Socio-economic and demographic characteristics of the sample

\begin{tabular}{llll}
\hline Descriptive statistics & Sample & & $\begin{array}{l}\text { Regional population } \\
\text { Variable }\end{array}$ \\
\cline { 2 - 3 } & Mean & Standard deviation & Mean \\
\hline Female & $52 \%$ & 0.499 & $50 \%$ \\
University education & $52 \%$ & 0.498 & $43 \%$ \\
Age & 53 years & 17 & 50 years \\
Monthly income per household & $40,000-60,000$ SEK & $10,000-20,000$ & 38,000 SEK \\
\hline
\end{tabular}

respondents were also asked whether they perceived themselves as having more knowledge about landslides and their consequences than people in general. 12 percent of the respondents claimed that this was the case. Hence, although about one fifth of the respondents report that they, or someone they know, have some experience of landslides the majority of the participants do not have any personal experience or much knowledge about landslide risks.

How landslide risks are valued may not only be affected by the expected impacts of such events, but also by the probability of an event, and by attitudes towards uncertain outcomes. In the survey, the risk introduced to participants varied between the scenarios, where the probability of the occurrence of a landslide was alternated to either increase or decrease every other question. The respondents were further asked about their self-perceived willingness to take risks in general, and in different domains (health, the environment, finances and safety). The results indicate that respondents are more willing to take risks in general than in relation to a specific area. Furthermore, the responses indicate that participants are less willing to accept risks affecting the health and safety of others than themselves.

\section{Estimation Results and Discussion}

The data set contains 6048 observations, each of the 504 respondents answered 12 choice sets. In half of the choice sets, in the follow-up questions, only the probability of a landslide changed, while attributes and levels were identical as in the preceding choice set. When respondents were asked whether they would like to change their choice from the previous question, most participants chose to stick with their original choice although the changes in probabilities were substantial, from ten to either one or fifty percent probability that a landslide would occur during the coming ten years. In about 20 percent of the followup questions, respondents changed their choice while in about 70 percent they did not, and in about 10 percent respondents reported that they did not know.

The business as usual alternative was chosen in 13 percent of the choice sets. The probability that the business-as-usual alternative was chosen was, to some extent, related to the stated probability of a landslide. When the probability of a landslide was increased to 50 percent the probability that the business-as-usual alternative was chosen remained the same as in the first choice set (10 percent). When the presented probability of a landslide instead was reduced to one percent the proportion of the respondents that chose the business-as-usual doubled however to 22 percent.

In the econometric analysis we apply a Random Parameter Logit (RPL) model. This model specification is preferred (over the Multinomial Logit model) since the dataset displays heterogeneity in taste, indicated by the statistically significant standard deviations of the estimated parameters, see Table 5. The results from estimating the RPL model 
Table 5 Results from estimating the RPL model

\begin{tabular}{lll}
\hline RPL Model & & \\
\hline Variable & Coefficient (s.e.) & Standard deviation \\
Fee & $-0.0002(0.000)^{* * *}$ & Fixed \\
No impact on infrastructure & $0.153(0.054)^{* * *}$ & $0.557^{* * *}$ \\
Limited impact on infrastructure (public roads) & $0.100(0.154)$ & 0.867 \\
No impact on human life & $1.864(0.119)^{* * *}$ & $3.207^{* * *}$ \\
Limited impact on human life (10 individuals affected) & $0.796(0.146)^{* * *}$ & 0.183 \\
No impact on the environment & $0.866(0.070)^{* * *}$ & $1.927^{* * *}$ \\
No impact on societal services & $0.870(0.068)^{* * *}$ & $1.571^{* * *}$ \\
Business as usual & $-1.994(0.295)^{* * *}$ & $5.819^{* * *}$ \\
Probability of occurrence low $*$ business as usual & $1.930(0.140)^{* * *}$ & Fixed \\
Probability of occurrence high $*$ business as usual & $-0.201(0.141)$ & Fixed \\
Simulated Log-likelihood value & -4153.174 & \\
Number of Halton draws & 2000 & \\
Pseudo $R^{2}$ & 0.375 & \\
BIC & 8340.3 \\
Number of parameters & 17 & \\
Number of observations & 6048 \\
\hline
\end{tabular}

***, **, * statistical significance levels at $1 \%, 5 \%$, and $10 \%$, respectively

presented in Table 5 were estimated using Nlogit 5 software and 2000 Halton draws. For more details about the RPL model, see Train (2003) and Hensher and Greene (2003). ${ }^{2}$

The utility coefficients for the attributes - impacts on human life, the environment, societal services, and infrastructure - are random coefficients (for variable definitions, see appendix A, Table 7). The model was estimated under different distributional assumptions, including the normal, uniform and triangular distribution. By comparing the simulated loglikelihood values, Mc Fadden pseudo R-square and the Akaike information criteria, the model assuming that all these utility coefficients follow a uniform distribution seemed to fit the data best (although differences were quite small). The cost coefficient Fee and the constant (equal to one for Alternative C, Business As Usual) are assumed to be non-random.

We are aware that the assumption of a non-random cost coefficient is restrictive. One way to overcome problems associated with deriving WTP from random preference-space coefficient attributes is to estimate the model in WTP space instead (Greene and Hensher 2009; Scarpa et al. 2008; Train and Weeks, 2005). However, the model estimated in WTP-space (using Nlogit as well as Stata) did not converge (Balcombe et al. 2009). ${ }^{3}$ Therefore, all WTPs presented here are estimated in utility space (still assuming the cost parameter to be fixed).

\footnotetext{
${ }^{2}$ The Generalised Mixed Logit model was also considered as it can also account for scale heterogeneity (Train and Weeks 2005; Louviere and Eagle 2006; Greene and Hensher 2010). If variance (i.e. scale) heterogeneity exists it can produce bias in welfare measures if not accounted for (Adamowicz et al. 2008). No scale heterogeneity was however identified, implying that the model reverts back to the RPL model.

${ }^{3}$ Unfortunately, we failed to achieve convergence due to problems with flat likelihood function also after trying the following recommendations suggested by our reviewer: scaling the cost variable (fee) by 1000 , use of both random and Halton draws, allowing for correlation of random coefficients, and by varying the order of variables (Palma et al. 2020).
} 
The results reveal that overall the respondents' valuation of reducing the risk of negative impacts from landslides are positive and statistically significant. All attribute coefficients except for limited impact on infrastructure (public roads) are statistically significant at the one percent level. All random coefficients have positive signs, indicating that the probability of choosing an alternative is increased when the attribute appears in the alternative, compared to the business-as-usual alternative. The reference levels of the attributes are: large impacts on infrastructure (damages to a motorway, highway and/or railway for 30 days), large impacts on human life (50 individuals affected by landslides), negative impact on the environment and on societal services (reduced for 30 days). The interpretation of a positive sign for the attributes is that respondents prefer no damages to infrastructure, no impact on human life or limited impact on human life (only ten individuals affected), over 50 individuals affected by a landslide. The respondents also prefer the environment not to be polluted by a landslide. In addition, maintaining important societal services is preferred over having important societal services reduced for 30 days. Finally, the cost coefficient estimate fee is negative implying that the respondents of course prefer low fees over high. The results also indicate that the respondents have tendencies to avoid choosing the business-as-usual alternative of doing nothing to reduce the risk of landslides.

To examine whether the probability of a landslide seem to have any impact on the willingness to contribute to reducing the expected damage from a landslide, the probability parameters were interacted with the business-as-usual alternative. The estimated low-risk coefficient is positive and statistically significant, indicating that the probability of choosing the business-as-usual alternative increases as the stated probability of landslides decreases. There is no statistically significant evidence that a higher risk would increase the willingness to pay to avoid the negative impacts of landslides. This somewhat surprising lack of statistical significance should be interpreted with care. One possible explanation for this lack of statistical significance is that the respondents did not consider the presented increase of 50 percent realistic.

The statistically significant standard deviations for pertaining infrastructure (except for no damages to public roads), impacts on human life (except for limited impact on human life), the environment and societal services, imply preference heterogeneity.

Additional model specifications have been tested for; attribute parameters have been interacted with the business-as-usual parameter and with income, university education, age, gender, previous experience and knowledge of landslides. None of these proved however to be statistically significant and they are therefore omitted from the results presented here. The lack of statistical significance of the income and education interaction coefficients implies that the preferences of those with higher income levels and/or education levels are not different from those with lower income and/or education levels. Remembering the overrepresentation of individuals with higher incomes and education in the sample, there is thus no evidence that the problems caused by this selection is severe. The attribute levels were also interacted with the level of risk presented in the follow up choice-set but since the statistical significance of these interactions was limited they are omitted from the model presented here. The attribute coefficient estimates proved to be stable and did not change substantially with respect to signs, sizes or statistical significance across model specifications. 
Table 6 Mean WTP estimates (Euros in parenthesis)

\begin{tabular}{|c|c|c|c|c|c|c|c|c|}
\hline \multirow{3}{*}{$\begin{array}{l}\text { Attributes } \\
\begin{array}{l}\text { No impact on infra- } \\
\text { structure }\end{array}\end{array}$} & \multicolumn{4}{|l|}{$1 \%$ probability } & \multicolumn{4}{|l|}{$10 \%$ probability } \\
\hline & \multirow{2}{*}{$\begin{array}{l}\text { Mean WTP } \\
87(9)\end{array}$} & \multirow{2}{*}{$\begin{array}{l}\text { s.e } \\
195\end{array}$} & \multicolumn{2}{|c|}{$\begin{array}{l}95 \% \text { confidence } \\
\text { interval }\end{array}$} & \multirow{2}{*}{$\begin{array}{l}\text { Mean WTP } \\
695^{* *}(70)\end{array}$} & \multirow{2}{*}{$\begin{array}{l}\text { s.e } \\
276\end{array}$} & \multicolumn{2}{|c|}{$\begin{array}{l}95 \% \text { confidence } \\
\text { interval }\end{array}$} \\
\hline & & & $-295,2$ & 469,2 & & & 154,04 & 1235,96 \\
\hline $\begin{array}{l}\text { Limited impact on } \\
\text { infrastructure } \\
\text { (public roads) }\end{array}$ & $-268(27)$ & 411 & $-537,56$ & 1073,56 & $701(70)$ & 648 & $-569,08$ & 1971,08 \\
\hline $\begin{array}{l}\text { No impact on human } \\
\text { life }\end{array}$ & $2245 * * *(225)$ & 469 & 1325,76 & 3164,24 & $4694 * * *(469)$ & 1197 & 2347,88 & 7040,12 \\
\hline $\begin{array}{l}\text { Limited impact on } \\
\text { human life }\end{array}$ & $1197 * * *(120)$ & 454 & 307,16 & 2086,84 & $1763 * *(176)$ & 751 & 291,04 & 3234,96 \\
\hline $\begin{array}{l}\text { No impact on the } \\
\text { environment }\end{array}$ & $1676 * * *(168)$ & 352 & 986,08 & 2365,92 & $2437 * * *(244)$ & 607 & 1247,28 & 3626,72 \\
\hline $\begin{array}{l}\text { No impact on soci- } \\
\text { etal services }\end{array}$ & $1607 * * *(161)$ & 325 & 970 & 2244 & $2451 * * *(245)$ & 595 & 1284,8 & 3617,2 \\
\hline
\end{tabular}

$* * *, * *, *$ indicate statistical significance levels at $1 \%, 5 \%$, and $10 \%$, respectively

\section{Marginal Willingness to Pay}

The willingness to trade-off between any two attributes is the ratio of their respective coefficients, and the marginal willingness to pay (WTP) for each attribute is computed as the negative of the coefficient of that attribute, divided by the fee coefficient. The WTPs are estimated in Swedish crowns (SEK), while corresponding WTPs in Euros are presented in parentheses in Table $6 .{ }^{4}$ The marginal WTPs are calculated for one and ten percent probability. The RPL model estimations on which these WTP calculations are based are presented in full in the appendix (Tables 8, 9 and 10). Since we did not find any statistically significant support for the notion that cost affects choice for the 50 percent probability model, we did not estimate marginal WTPs for this model.

The WTPs of all attributes except infrastructure are statistically significant at one percent in both models. Although the mean WTPs are higher for the ten than for the one percent probability model, all confidence intervals except for no infrastructure (which is only statistically significant for 10 percent) are overlapping and no conclusions about any differences in WTPs can thus be drawn. There are considerable differences in marginal WTPs for the different attributes. Acting to reduce risk of landslide impacts on human life is considered the most important for our respondents, while there is limited support for any willingness to accepts costs to reduce impacts on infrastructure. Flügel et al. (2015) who studied the valuation of land slide risk reductions in the setting of car accidents also found that human risks are considered important, although they reported a somewhat lower WTP of $€ 98^{5}$ (909 NOK/SEK). Our participants are also willing to pay substantial amounts for reducing the risk that

\footnotetext{
4 The WTPs in Euros were calculated using an exchange rate of $10 \mathrm{SEK} / €$

5 The value of NOK corresponds to the value of SEK.
} 
a landslide would cause harmful substances to be spread to the environment via the water, air and soil and to avoid negative impacts on societal services. Damages on infrastructure is thus considered the least important, which is consistent with the findings of Spegel (2017), who analyze the preferences for the impacts of floods in the same region.

\section{Concluding Remarks}

This paper has applied a choice experiment to analyze the preferences for the consequences of landslides, including impacts on infrastructure, but also on less studied impacts such as on human life and safety, the environment and important societal services. Data was retrieved from a web panel implemented in the landslide prone valley surrounding the Göta River in southwest of Sweden. The overall finding is that reducing the risk of landslides would have a positive impact on individuals' utility; responses indicate that respondents are willing to pay an additional annual fee to reduce the consequences of landslides. Participants prioritize preventing negative impacts on humans over maintaining important societal services and environmental status, which is consistent with previous studies (Birol et al. 2009; Veronesi et al. 2014). Although these studies are not entirely comparable since the attributes and settings differ, the general indication from the economics literature estimating the value of fatal risks (Wang and Mullahy 2006; Alberini and Chiabai 2007) and from the literature on environmental valuation (Roberts et al. 2008; Lew et al. 2010) is that fatal risks are usually valued higher than environmental risks. Preventing damages to infrastructure is the least concerning area, according to our results.

The differences between how different impacts are valued suggest that there are differences between the relative valuations of impacts expressed by the citizens and in the model for risk assessment applied by the national authority. These results indicate that instead of giving all impacts equal weight, impacts on human life should be prioritized over impacts on transport infrastructure.

The valuation of different impacts from natural disasters is however highly case dependent, policymakers need to make decisions in an uncertain world with scarce resources and to make a case study for each and every decision would be very time consuming and costly. The analysis in this paper should be seen as an attempt to estimate the relative importance of the different impacts of landslides in general. By complementing these results with more site-specific case studies it would be possible to study to what extent and under which circumstances the relative ordering of impacts found in this study may hold also for specific cases. This is thus an arena for important further research. 


\section{Appendix}

Table 7 Definition of variables

\begin{tabular}{|c|c|c|c|}
\hline Variable & Definition & Min & $\operatorname{Max}$ \\
\hline Fee & Municipal fee in SEK to be paid each year for ten years & 0 & 1500 \\
\hline No impact on infrastructure & $\begin{array}{l}\text { No damage to infrastructure } \\
\text { Reference level: Damages to infrastructure that disa- } \\
\text { bles Motorway/highway/railroad disabled for } 30 \text { days }\end{array}$ & 0 & 1 \\
\hline Limited impact on infrastructure & $\begin{array}{l}\text { Public road/avenue disabled for } 30 \text { days } \\
\text { Reference level: Damages to infrastructure that disa- } \\
\text { bles Motorway/highway/railroad disabled for } 30 \text { days }\end{array}$ & 0 & 1 \\
\hline No impact on life & $\begin{array}{l}\text { No individuals injured or diseased } \\
\text { Reference level: } 50 \text { individuals injured or diseased }\end{array}$ & 0 & 1 \\
\hline $\begin{array}{l}\text { Limited impact on humans ( } 10 \\
\text { individuals affected) }\end{array}$ & $\begin{array}{l}\text { Ten individuals injured or diseased } \\
\text { Reference level: } 50 \text { individuals injured or diseased }\end{array}$ & 0 & 1 \\
\hline No impact on the environment & $\begin{array}{l}\text { No pollution of the environment } \\
\text { Reference level: Pollution of the environment by harm- } \\
\text { ful substances spreading to the environment via the } \\
\text { water, air and/or soil }\end{array}$ & 0 & 1 \\
\hline No impact on societal services & $\begin{array}{l}\text { No loss of societal services } \\
\text { Reference level: Loss of societal services including } \\
\text { hospital, fire station/police station/school, which } \\
\text { reduces the society's ability to function for } 30 \text { days }\end{array}$ & 0 & 1 \\
\hline Business as usual & Refers to alternative $\mathrm{C}$ & 0 & 1 \\
\hline
\end{tabular}

Table 8 RPL model estimation -1 percent probability of occurrence

\begin{tabular}{lll}
\hline RPL Model & & \\
\hline Variable & Coefficient (s.e.) & Standard deviation \\
\hline Fee & $-0.0005(0.000)^{* * *}$ & Fixed \\
No impact on infrastructure & $-0.002(0.089)$ & 0.001 \\
Limited impact on infrastructure (public roads) & $-0.277(0.289)$ & 0.121 \\
No impact on humans & $1.099(0.143)^{* * * *}$ & $2.347^{* * *}$ \\
Limited impact on humans (10 individuals affected) & $0.870(0.265)^{* * *}$ & 0.032 \\
No impact on the environment & $0.707(0.097)^{* * *}$ & 0.789 \\
No impact on societal services & $0.723(0.102)^{* * * *}$ & 0.667 \\
Business as usual & $-2.599(0.591)^{* * *}$ & $8.084 * * *$ \\
Model fit & & \\
Log-likelihood value & -1296.955 & \\
$\quad$ Pseudo $R^{2}$ & 0.219 & \\
BIC & 2623.9 & \\
Number of parameters & 15 & \\
Number of observation & 1512 & \\
\hline
\end{tabular}

$* * *, * *, *$ statistical significance levels at $1 \%, 5 \%$, and $10 \%$, respectively 
Table 9 RPL model estimation -10 percent probability of occurrence

\begin{tabular}{lll}
\hline RPL Model & & \\
\hline Variable & Coefficient & Standard deviation \\
\hline Fee & $-0.0003(0.000)^{* * *}$ & Fixed \\
No impact on infrastructure & $0.187(0.054)^{* * *}$ & 0.029 \\
Limited impact on infrastructure (public roads) & $0.189(0.165)$ & 0.249 \\
No impact on humans & $1.262(0.081)^{* * *}$ & $1.433^{* * *}$ \\
Limited impact on humans (10 individuals affected) & $0.474(0.165)^{* * *}$ & 0.325 \\
No impact on the environment & $0.655(0.056)^{* * *}$ & $0.545^{* * *}$ \\
No impact on societal services & $0.659(0.056)^{* * *}$ & 0.032 \\
Business as usual & $-1.763(0.285)^{* * *}$ & $4.515^{* * * *}$ \\
Model fit & & \\
Log-likelihood value & -2337.093 & \\
$\quad$ Pseudo $R^{2}$ & 0.297 & \\
BIC & 4704.2 & \\
Number of parameters & 15 & \\
Number of observation & 3024 \\
\hline
\end{tabular}

$* * *, * *, *$ statistical significance levels at $1 \%, 5 \%$, and $10 \%$, respectively

Table 10 RPL model estimation - Subsample 50 percent probability of occurrence

\section{RPL Model}

\begin{tabular}{lll}
\hline Variable & Coefficient & Standard deviation \\
\hline Fee & $-0.0001(0.000)$ & Fixed \\
No impact on infrastructure & $0.228(0.084)^{* * *}$ & 0.163 \\
Limited impact on infrastructure (public roads) & $0.248(0.264)$ & 0.008 \\
No impact on humans & $1.094(0.086)^{* * *}$ & 0.042 \\
Limited impact on humans (10 individuals affected) & $0.474(0.394)$ & 0.005 \\
No impact on the environment & $0.570(0.081)^{* * *}$ & 0.011 \\
No impact on societal services & $0.603(0.086)^{* * *}$ & $0.436^{*}$ \\
Business as usual & $-0.018(0.201)$ & 0.364 \\
Model fit & & \\
Log-likelihood value & -1259.440 & \\
Pseudo $R^{2}$ & 0.242 & \\
BIC & 2548.9 & \\
Number of parameters & 15 & \\
Number of observation & 1512 & \\
\hline
\end{tabular}

$* * *, * *, *$ statistical significance levels at $1 \%, 5 \%$, and $10 \%$, respectively 
Funding Open access funding provided by Lulea University of Technology. The work was supported by the European Union's Seventh Framework Program through the grant to the budget of the Integrated Project STAR-FLOOD, Contract 308364.

Data Availability The datasets generated during and/or analysed during the current study are available from the corresponding author on reasonable request.

Code Availability Not applicable

\section{Declarations}

\section{Conflicts of Interest Not applicable}

Open Access This article is licensed under a Creative Commons Attribution 4.0 International License, which permits use, sharing, adaptation, distribution and reproduction in any medium or format, as long as you give appropriate credit to the original author(s) and the source, provide a link to the Creative Commons licence, and indicate if changes were made. The images or other third party material in this article are included in the article's Creative Commons licence, unless indicated otherwise in a credit line to the material. If material is not included in the article's Creative Commons licence and your intended use is not permitted by statutory regulation or exceeds the permitted use, you will need to obtain permission directly from the copyright holder. To view a copy of this licence, visit http://creativecommons.org/licenses/by/4.0/.

\section{References}

Adamowicz W, Bunch D, Cameron TA, Dellaert BGC, Hanneman M, Keane M, Louviere J, Meyer R, Steenburgh T, Swait J (2008) Behavioral frontiers in choice modeling. Mark Lett 19(3-4):215-228. https://doi.org/10.1007/s11002-008-9038-1

Allaire M (2018) Socio-economic impacts of flooding: A review of the empirical literature. Water Security 3:18-26

Alberini A, Chiabai A (2007) Urban environmental health and sensitive populations: how much are the Italians willing to pay to reduce their risks? Reg Sci Urban Econ 37(2):239-258. https://doi.org/10.1016/j. regsciurbeco.2006.08.008

Baert M, Kervyn M, Kagou AD, Guedjeo CS, Vranken L, Mertens K (2020) Resettlement preferences from landslide prone areas in Cameroon: Willingness to move, reasons to stay. Land Use Policy 95:103975. https://doi.org/10.1016/j.landusepol.2019.04.036

Balcombe K, Chalak A, Fraser I (2009) Model selection for the mixed logit with Bayesian estimation. J Environ Econ Manag 57(2):226-237. https://doi.org/10.1016/j.jeem.2008.06.001

Bartczak A, Meyerhoff J (2013) Valuing the chances of survival of two distinct Eurasian lynx populations in Poland - do people want to keep the doors open? J Environ Manage 129:73-80. https://doi.org/10. 1016/j.jenvman.2013.05.046

Bethlehem JG (2009) Applied Survey Methods, A Statistical Perspective. John Wiley \& Sons, Hoboken, New Jersey

Birol E, Koundouri P, Kountouris K (2009) Using the choice experiment method to inform river management in Poland: flood risk reduction versus habitat conservation in the Upper Silesia region. In Birol E, Koundouri P (Eds.), Choice Experiments Informing Environmental Policy A European Perspective. Cheltenham, Edward Elgar Publishing

Cadavid C, Ando AW (2013) Valuing preferences over storm water-management outcomes including improved hydrologic function. Water Resour Res 49:4114-4125. https://doi.org/10.1002/wrcr.20317

Charoenphong S (1991) Environmental calamity in southern Thailand's headwaters: Causes and remedies. Land Use Policy 8(3):185-188. https://doi.org/10.1016/0264-8377(91)90030-M

Corso PS, Hammit JK, Graham JD (2001) Valuing mortality-risk reduction: using visual aids to improve the validity of contingent valuation. J Risk Uncertain 23:165-184. https://doi.org/10.1023/A:1011184119 153

Drake B, Smart JCR, Termansen M, Hubacek K (2013) Public preferences for production of local and global ecosystem services. Reg Environ Change 13:649-659. https://doi.org/10.1007/s10113-011-0252-7 
Elgan HT, Leifman H (2013) Prevalence of adolescents who perceive their parents to have alcohol problems: A Swedish national survey using a web panel. Scand J Pub Health 41:680-683. https://doi.org/ $10.1177 / 1403494813491859$

Ferrini S, Scarpa R (2007) Designs with a-priori information for nonmarket valuation with choice-experiments. J Environ Econ Manag 53(3):342-363

Flügel S, Rizzi LI, Veisten K, Elvik R, De Dios Ortúzar J (2015) Car drivers' valuation of landslide risk reductions. Saf Sci 77:1-9. https://doi.org/10.1016/j.ssci.2015.03.006

Franceschinis C, Thiene M, Mattea S, Scarpa R (2020) Do information and citizens characteristics affect public acceptability of landslide protection measures? A latent class approach. In Filho WL, Jaco D (eds) Handbook of Climate Services. E-book, Chapter 25. Springer.

Greene HG, Hensher DA (2010) Does scale heterogeneity across individuals matter? An empirical assessment of alternative logit models. Transportation 37:413-428. https://doi.org/10.1007/ s11116-010-9259-Z

Harris AJL, Corner A (2011) Communicating Environmental Risks: Clarifying the Severity Effect in Interpretations of Verbal Probability Expressions. J Exp Psychol Learn Mem Cogn 37(6):1571-1578

Hensher DA, Greene WH (2003) The mixed logit model: The state of practice. Transportation 30:133-176. https://doi.org/10.1023/A:1022558715350

Hensher DA, Greene WH (2009) Valuation of travel timesavings in WTP and preference space in the presence of taste and scale heterogeneity. Institute of transport and Logistics Studies, University of Sydney, Sydney. https://doi.org/10.1007/s11116-010-9259-z

IPCC/Intergovernmental Panel on Climate Change (2014) Climate Change 2014: Synthesis Report. In Pachauri RK, Meyer LA (Eds.) Contribution of Working Groups I, II and III to the Fifth Assessment Report of the Intergovernmental Panel on Climate Change. Geneva, Switzerland: IPCC. ISBN 978-92-9169-143-2.

Kirschbaum DB, Adler R, Hong Y, Hill S, Lerner-Lam A (2010) A global landslide catalog for hazard applications: method, results and limitations. Nat Hazards 52:561-575. https://doi.org/10.1007/ s11069-009-9401-4

Kiilsgaard R, Bergdahl K, Öberg M, Helgesson H, Enell A (2015) Skredrisker i ett förändrat klimat Norsälven. Konsekvensanalys Norsälven, Del 3: Fördjupningsbilaga. SGI (Swedish Geotechnical Institute), Publikation 18-4, Linköping: SGI

Lew DK, Layton DF, Rowe RD (2010) Valuing enhancements to endangered species protection under alternative baseline futures: the case of the Steller Sea lion. Mar Resour Econ 25:133-154. https://doi.org/ $10.5950 / 0738-1360-25.2 .133$

Logar I, Brouwer R (2016) The effect of risk communication on welfare estimates and choice certainty in choice experiments. Water Resourc Econ 18:34-50. https://doi.org/10.1016/j.wre.2016.11.004

Louviere JJ, Eagle T (2006) Confound it! That pesky little scale constant messes up our convenient assumptions! Proc 2006 Sawtooth Software Conference, 211-228. Washington: Sequem

Mattea S, Franceschinis C, Scarpa R, Thiene M (2016) Valuing landslide risk reduction programs in the Italian Alps: The effect of visual information on preference stability. Land Use Policy 59:176-184. https://doi.org/10.1016/j.landusepol.2016.08.032

Mertens K, Jacobs L, Maes J, Poesen J, Kervyn M, Vranken L (2018) Disaster risk reduction among household exposed to landslide hazard: A crucial role for self-efficacy? Land Use Policy 75:77-91. https://doi.org/10.1016/j.landusepol.2018.01.028

Palma MA, Vedenov DV, Bessler D (2020) The order of variables, simulation noise, and accuracy of mixed logit estimates. Empirical Economics, pp 2049-2083. https://doi.org/10.1007/ s00181-018-1609-2

Rolfe J, Windle J (2015) Do respondents adjust their expected utility in the presence of an outcome certainty attribute in a choice experiment? Environ Resourc Econ 60(1):125-142. https://doi.org/10. 1007/s10640-014-9760-5

Roberts DC, Boyer TA, Lusk JL (2008) Preferences for environmental quality under uncertainty. Ecol Econ 66(4):584-593. https://doi.org/10.1016/j.ecolecon.2008.05.010

Rose JM, Bliemer MCJ (2013) Sample size requirements for stated choice experiments. Transportation 40(5):1021-1041. https://doi.org/10.1007/s11116-013-9451-z

Sándor Z, Wedel M (2001) Designing conjoint choice experiments using managers' prior beliefs. J Mark Res 38:430-444

Scarpa R, Rose JM (2008) Designs efficiency for nonmarket valuation with choice modelling: how to measure it, what to report and why. Australian J Agricult Resourc Econ 52:253-282

Scarpa R, Thiene M, Train K (2008) Utility in WTP space: A tool to address confounding random scale effects in destination choice to the Alps. Am J Agr Econ 90:994-1010 
Swedish Civil Contingencies Agency. 2021. Internet (accessed August 2021) https://www.msb.se/sv/ amnesomraden/skydd-mot-olyckor-och-farliga-amnen/naturolyckor-och-klimat/skred-ras-och-erosi on/.

Swedish Civil Contingencies Agency (2017) Tuveskredet, Göteborgs kommun, 30 november 1977. Internet (accessed 2017-08-15) https://www.msb.se/sv/Forebyggande/Naturolyckor/Skred-ras-ochslamstrommar/Exempel-skred-och-ras/Skred-Tuve/

Swedish Geotechnical Institute (2012) Skredrisker i Göta älvdalen i ett förändrat klimat. Slutrapport, Del 1 - Samhällskonsekvenser. Linköping: SGI

Swedish Geotechnical Institute. 2016. Skredrisk Göta älv. http://www.swedgeo.se/sv/samhallsplaneri ng--sakerhet/skredriskutredningar/gota-alv/ (Accessed 2017-04-03):

SOU (Official Reports of the Swedish Government) (2007) 60. Sweden facing climate change - threats and opportunities. Stockholm: Miljö- och energidepartmentet

Spegel E (2017) Valuing the reduction of floods - public official's versus citizen's preferences. Clim Risk Manag 18:1-14. https://doi.org/10.1016/j.crm.2017.08.003

Statistics Sweden, 2016. Folkmängd i riket, län, och kommuner 31 december 2016 och befolkningsförändringar 2016. http://www.scb.se/sv_/Hitta-statistik/Statistik-efter-amne/Befolkning/Befol kningens-sammansattning/Befolkningsstatistik/25788/25795/Helarsstatistik---Kommun-lan-ochriket/399348/ (Accessed 2017-07-18)

Svensson J (2013) Web panel surveys - Can they be designed and used in a scientifically sound way? 59th ISI World Statistics Congress 2013. Hong Kong

Thiene M, Shaw WD, Scarpa R (2017) Perceived risks of mountain landslides in Italy: stated choices for subjective risk reductions. Landslides 14:1077-1098. https://doi.org/10.1007/s10346-016-0741-3

Train K (2003) Discrete Choice Model with Simulation. Cambridge University Press, Cambridge

Train K, Weeks M (2005) Discrete choice models in preferences space and willing to-pay space. In Scarpa R, Alberini A (eds.) Applications of Simulation Methods in Environmental and Resource Economics, Chap. 1, 1-16. Dordrecht: Springer Publisher.

Veronesi M, Chawla F, Maurer Leinert M, J. (2014) Climate change and the willingness to pay to reduce ecological and health risks from wastewater flooding in urban centers and the environment. Ecol Econ 98:1-10. https://doi.org/10.1016/j.ecolecon.2013.12.005

Vlaeminck P, Maertens M, Isabirye M, Vanderhoydonks F, Poesenm J, Deckers J, Vranken L (2016) Coping with landslide risk through choice experiments for the mount Elgon region, Uganda. Land Use Policy 15:301-311. https://doi.org/10.1016/j.landusepol.2015.11.023

Vranken L, Van Turnhout P, Van Den Eeckhaut M (2013) Economic valuation of landslide damage in hilly regions: A case study from Flanders, Belgium. Sci Total Environ 447:323-333. https://doi. org/10.1016/j.scitotenv.2013.01.025

Wang H, Mullahy J (2006) Willingness to pay for reducing fatal risk by improving air quality: A contingent valuation study in Chongqing, China. Sci Total Environ 367(1):50-57. https://doi.org/10.1016/j.scito tenv.2006.02.049

Publisher's Note Springer Nature remains neutral with regard to jurisdictional claims in published maps and institutional affiliations. 